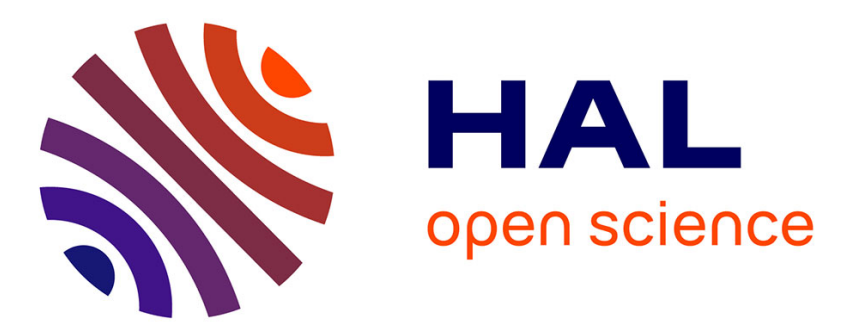

\title{
Feedback control of bilinear distributed parameter system by input-output linearization
}

\author{
Nouara Habrache, Ahmed Maidi, Jean Pierre Corriou
}

\section{To cite this version:}

Nouara Habrache, Ahmed Maidi, Jean Pierre Corriou. Feedback control of bilinear distributed parameter system by input-output linearization. International Journal of Modelling, Identification and Control, 2019, 10.1504/IJMIC.2019.099812 . hal-02383372

\section{HAL Id: hal-02383372 https://hal.science/hal-02383372}

Submitted on 27 Nov 2019

HAL is a multi-disciplinary open access archive for the deposit and dissemination of scientific research documents, whether they are published or not. The documents may come from teaching and research institutions in France or abroad, or from public or private research centers.
L'archive ouverte pluridisciplinaire HAL, est destinée au dépôt et à la diffusion de documents scientifiques de niveau recherche, publiés ou non, émanant des établissements d'enseignement et de recherche français ou étrangers, des laboratoires publics ou privés. 
archives-ouvertes

\title{
Feedback control of bilinear distributed parameter system by input-output linearization
}

\author{
Jean Pierre Corriou, Nouara Habrache, Ahmed Maidi, Jean-Pierre Corriou
}

\section{To cite this version:}

Jean Pierre Corriou, Nouara Habrache, Ahmed Maidi, Jean-Pierre Corriou. Feedback control of bilinear distributed parameter system by input-output linearization. International Journal of Modelling, Identification and Control, Inderscience, 2019. hal-02383372

\section{HAL Id: hal-02383372 \\ https://hal.archives-ouvertes.fr/hal-02383372}

Submitted on 27 Nov 2019

HAL is a multi-disciplinary open access archive for the deposit and dissemination of scientific research documents, whether they are published or not. The documents may come from teaching and research institutions in France or abroad, or from public or private research centers.
L'archive ouverte pluridisciplinaire HAL, est destinée au dépôt et à la diffusion de documents scientifiques de niveau recherche, publiés ou non, émanant des établissements d'enseignement et de recherche français ou étrangers, des laboratoires publics ou privés. 


\title{
Feedback control of bilinear distributed parameter system by input-output linearization
}

\section{Nouara Habrache and Ahmed Maidi*}

Laboratoire de Conception et Conduite des Systèmes de Production,

Université Mouloud MAMMERI,

15000 Tizi-Ouzou, Algérie.

E-mail: nouara.habrache90@gmail.com

E-mail: ahmed.maidi@gmail.com

*Corresponding author

\section{Jean-Pierre Corriou}

Laboratoire Réactions et Génie des Procédés, UMR 7274-CNRS, Lorraine University,

ENSIC 1, rue Grandville, BP 20451,

54001 Nancy Cedex, France.

E-mail: jean-pierre.corriou@univ-lorraine.fr

\begin{abstract}
In this paper, a control law that enforces the tracking of a boundary controlled output for a bilinear distributed parameter system is developed in the framework of geometric control. The dynamic behavior of the system is described by two weakly coupled linear hyperbolic partial differential equations. The stability of the resulting closed-loop system is investigated based on eigenvalues of the spatial operator of a weakly coupled system of balance equations. It is shown that, under some reasonable assumptions, the stability condition is related to the choice of the tuning parameter of the control law. The performance of the developed control law is demonstrated, through numerical simulation, in the case of a co-current heat exchanger. The control objective is to control the outlet cold fluid temperature by manipulating its velocity. Both tracking and disturbance rejection problems are considered.
\end{abstract}

Keywords: partial differential equation; bilinear distributed parameter system; geometric control; characteristic index; exponential stability; co-current heat exchanger.

Biographical notes: Nouara Habrache was born in Algeria in 1990. She received the Master degree in control from Mouloud MAMMERI University of Tizi-Ouzou, Algeria, in 2013. Currently, she is pursuing a Ph.D. degree at the Department of Automatic Control of the same university. Her current research interests concern the control of bilinear distributed parameter systems with application to chemical processes.

Ahmed Maidi, born in 1974 in Algeria, graduated in Automatic Control Engineering (State Engineer) from Hydrocarbons and Chemistry National Institute (INHC), Boumerdès, Algeria (1997). He received the Magister degree in Electrical Engineering from M'Hamed BOUGARA, Boumerdès, Algeria (2001). He obtained his Ph.D. in control engineering from Mouloud MAMMERI University, Tizi-Ouzou, Algeria (2008) in collaboration with the Reaction and Process Engineering Laboratory, CNRS, ENSIC, Nancy, France. Currently, he is Professor in the Department of Automatic Control at Mouloud MAMMERI University, Algeria. His primary research interests are in modeling, simulation, optimization and control of distributed parameter systems.

Jean-Pierre Corriou, born in France in 1950, received his chemical engineer diploma from Ecole Centrale, Paris (1973) and Ph.D. from University Paris 6 (1979). He was Assistant-Professor at Ecole Centrale, Paris (1973-1988), then Professor of applied mathematics at National School of Chemical Industries, ENSIC, University of Lorraine, Nancy (1988-2014). From 2014 to 2016, he was director of simulation in a new process company, Ypso-Facto, Nancy. He is currently emeritus professor of University of Lorraine. He has published more than 100 articles, mainly in chemical engineering and control, three books about process control (including Process Control-Theory and Applications, Springer, London 2004) and numerical methods and optimization. His research interests include dynamic optimization, model predictive control, nonlinear geometric control and control of PDEs together with applications in chemical engineering. 


\section{Introduction}

Although several interesting control strategies have been developed for nonlinear distributed parameter systems (DPSs) (Chen et al., 2001; Dai et al., 2015; Wang et al., 2011; Christofides, 2001a,b; Dubljevic et al., 2004; Padhi and Faruque Ali, 2009; Maidi and Corriou, 2011, 2014; Ding and Gu, 2010), control design for this class remains a challenging problem (Christofides, 2001b). If, for linear DPSs, a general control theory is developed by means of semigroup theory (Curtain and Zwart, 1995), for nonlinear DPSs, this is difficult and the investigation is made by assuming certain particular classes. Among these classes, can be cited the first-order hyperbolic PDEs (Hanczyc and Palazoglu, 1995; Christofides and Daoutidis, 1996; García-Sandoval et al., 2008; Gundepudi and Friedly, 1998), the quasilinear parabolic partial differential equations (PDEs) (Dubljevic et al., 2004) and the nonlinear parabolic PDE (Maidi and Corriou, 2014).

An important class of DPSs encountered in a wide variety of practical applications is described by coupled linear hyperbolic PDEs issued from first principles (Bartecki, 2016). In this case, two kinds of DPSs can be distinguished: strongly and weakly coupled (Bartecki, 2016). When both temporal and spatial derivatives of different state variables are involved in each equation of the model, the system is said to be strongly coupled. In the other case, when each equation of the model contains only the temporal and spatial derivatives of the same state variable, the system is weakly coupled. Note that, under certain assumptions, a strongly coupled system can be transformed into a weakly one by means of a decoupling procedure (Bartecki, 2016).

Heat exchangers, electrical transmission lines, irrigation channels and transportation pipelines are some examples of DPSs whose dynamic behavior is described by coupled hyperbolic PDEs (Xu and Dubljevic, 2016; Bartecki, 2016). For these DPSs, for certain practical considerations, some parameters of the model are taken as control variables. As an example, in the case of heat exchanger, manipulating a fluid velocity is more practical than manipulating its inlet temperature. Thus, the system is turned into a bilinear one, which represents another interesting particular class of nonlinear DPSs.

When a parameter is taken as a manipulated variable to control a boundary output, a weakly coupled DPS is characterized by a finite characteristic index (Christofides and Daoutidis, 1996), which is a generalization of the notion of the relative degree of lumped parameter systems (LPSs) (Isidori, 1995). In addition, the stability analysis of a weakly coupled DPS can be done easily by examining the eigenvalues of the spatial operator. These interesting properties motivate the use of geometric control for bilinear DPSs to design a control law following the late lumping approach.

Designing a controller for a DPS can be done using two possible approaches (Ray, 1989; Christofides, 2001a): early lumping and late lumping.
The early lumping approach consists in approximating the PDE model by a set of ordinary differential equations (ODEs), i.e., the DPS is reduced to a lumped parameter system (LPS). This approach can be seen as model reduction. The equivalent LPS model is obtained by approximating either the PDEs or their solutions (Wang et al., 2011; Ray, 1989; Li and Qi, 2010). The resulting reduced model is then used to design the controller in the framework of the control theory of LPSs. However, the early lumping approach presents significant drawbacks. First, reducing the DPS to LPS does not preserve the fundamental control properties (controllability, observability and stability) of the original DPS (Ray, 1989; Singh and Hahn, 2007). Secondly, ensuring a good approximation of the distributed behavior of DPS requires a high order reduced model, which makes the control design step more difficult. Thirdly, the dimension of the resulting controller is important, which makes it difficult to implement. In addition, neglecting the distributed nature of the DPS often leads to a controller with a poor performance (Christofides, 2001a).

The late lumping approach represents the effective alternative to the early lumping approach (Christofides and Daoutidis, 1996; Christofides, 2001a). This approach directly uses the PDEs model, without any reduction, for the design of the controller. Therefore, the distributed nature of the DPS and its fundamental control properties are preserved (Ray, 1989; Christofides, 2001a). This approach yields a controller of distributed nature that enhances the performance in closed loop (Christofides and Daoutidis, 1996).

In this work, following the late lumping approach, a control law that enforces both output tracking and disturbance rejection is developed for a bilinear DPS in the framework of geometric control. By assuming a boundary output, it is shown that the obtained control law, which is of finite dimensional nature, yields a time-varying bilinear system in closed loop. Then, based on the mathematical properties of the spatial operator of the resulting closed-loop system, the stability condition is established. The performance of the developed control law is evaluated in the case of a cocurrent heat exchanger. The problem is to control the outlet temperature of the cold fluid by manipulating its inlet velocity.

The paper is structured as follows: The control problem of a bilinear DPS is presented in Section 2. Section 3 gives the main results concerning the stability of coupled linear hyperbolic PDEs. Section 4 is devoted to the control law design and to the stability analysis of the resulting closed-loop system. Numerical simulation results that show the performance of the control law, in the case of a co-current heat exchanger, are reported in Section 5. Section 6 concludes the paper. 


\section{Problem formulation}

Let us consider a linear $2 \times 2$ system issued from first principles balances described by the following hyperbolic coupled PDEs (Bartecki, 2016)

$$
\begin{aligned}
& \frac{\partial x_{1}(z, t)}{\partial t}=-u_{1} \frac{\partial x_{1}(z, t)}{\partial z}+\alpha_{1}\left(x_{2}(z, t)-x_{1}(z, t)\right) \\
& \frac{\partial x_{2}(z, t)}{\partial t}=-u_{2} \frac{\partial x_{2}(z, t)}{\partial z}+\alpha_{2}\left(x_{1}(z, t)-x_{2}(z, t)\right)
\end{aligned}
$$

with the following boundary conditions

$$
\begin{aligned}
& x_{1}(0, t)=x_{10} \\
& x_{2}(0, t)=x_{20}
\end{aligned}
$$

and initial conditions

$$
\begin{aligned}
& x_{1}(z, 0)=x_{1}^{0}(z) \\
& x_{2}(z, 0)=x_{2}^{0}(z)
\end{aligned}
$$

In this model, $t \in[0, \infty)$ and $z \in[0, l]$ represent the time and spatial variables, respectively. $\alpha_{1}, \alpha_{2}, x_{10}$ and $x_{20}$ are constant positive parameters. The variables $u_{1}$ and $u_{2}$ can be assumed as manipulated variable and disturbance, respectively and vice versa, depending on the considered control configuration. $x_{1}$ and $x_{2}$ are the state variables assumed to be in Hilbert space $L^{2}([0, l])$ while $x_{1}^{0}$ and $x_{2}^{0}$ are the initial spatial profiles.

To simplify the presentation, it is assumed in the following that our aim is to control the following boundary output

$$
y(t)=x_{1}(l, t)
$$

by manipulating the variable $u_{1}$ whereas $u_{2}$ is a disturbance.

Assuming this control configuration, the model (1)(6) represents a bilinear DPS (Ouzahra, 2016; Bühler and Franke, 1980). This particular class of DPSs is termed weakly coupled or decoupled systems since the terms that contain derivatives are not coupled (Bartecki, 2016).

To solve this formulated control problem, the following assumptions are made.

Assumption 1: The spatial profile $x_{1}(z, t)$ is a monotonic function with respect to $z$ at given $t$, furthermore assumed increasing (Ayres, 1952).

Assumption 2: At $z=0$, the boundaries conditions are such that $x_{2}(0, t)-x_{1}(0, t)>0$, that is, $x_{20}-x_{10}>$ 0 .
Remark 1: For the distributed parameter system (12 ), since $u_{1}, u_{2}, \alpha_{1}$ and $\alpha_{2}$ are positive parameters, assumption 2 implies that $x_{2}(z, t)-x_{1}(z, t)>0$ for $z \in$ $[0, l]$.

Before addressing the control law design, the stability issue of the system (1)-(6) is discussed in the following section.

\section{Stability of linear hyperbolic systems of balance laws}

The stability of the semigroup or of its generator (operator), i.e. the stability of DPS, can be investigated using some tools from spectral theory (Engel and Nagel, 2006). Thus, if all the eigenvalues of the operator are negative real or complex with negative real part, the semigroup is stable, i.e. the DPS is stable.

Let us write the PDEs model (1-6) under the following operator form

$$
\frac{\partial x(z, t)}{\partial t}=\mathcal{H} x(z, t)
$$

where $x(z, t)=\left[x_{1}(z, t), x_{2}(z, t)\right]^{T}$ is the vector of state variables and the spatial operator $\mathcal{H}$ is defined as follows

$$
\mathcal{H}=\mathcal{A} \frac{\partial}{\partial z}+\mathcal{B}
$$

with

$$
\mathcal{A}=\left[\begin{array}{rr}
-u_{1} & 0 \\
0 & -u_{2}
\end{array}\right]
$$

and

$$
\mathcal{B}=\left[\begin{array}{rr}
-\alpha_{1} & \alpha_{1} \\
\alpha_{2} & -\alpha_{2}
\end{array}\right]
$$

The stability of the linear hyperbolic systems issued from balance laws has been investigated in the literature (Russell, 1978; Diagne et al., 2012). The aim of this section is to give the condition that ensures the exponential stability developed based on the spectral theory (Engel and Nagel, 2006). This theory provides the qualitative behavior of the semigroup generated by the spatial operator $\mathcal{H}$ (Engel and Nagel, 2006).

Given the boundary conditions (3)-(4), since the eigenvalues of the matrix $\mathcal{A}$ are negative, the eigenvalues of the spatial operator $\mathcal{H}$ are complex and equal to (Christofides and Daoutidis, 1996; Russell, 1978)

$$
\lambda_{k}=-\infty+k \pi i, \quad k=-\infty, \ldots,+\infty
$$

with $i$ is the imaginary unit, which implies that the system (8) is exponentially stable, i.e., the spatial operator $\mathcal{H}$ generates a stable semigroup. Consequently, the PDEs model (1)-(6) is exponentially stable if the parameters $u_{1}$ and $u_{2}$ are positive. 


\section{Control law design and closed loop stability analysis}

In this section, the control problem formulated above is solved in the framework of geometric control using the characteristic index concept introduced by (Christofides and Daoutidis, 1996), which is a generalization of the relative degree of a finite dimensional system (Isidori, 1995).

\subsection{Control law design}

The calculation of the first time derivative of the controlled output (7) yields

$$
\begin{aligned}
\frac{d y(t)}{d t} & =\left.\frac{\partial x_{1}(z, t)}{\partial t}\right|_{z=l} \\
& =-\left.u_{1} \frac{\partial x_{1}(z, t)}{\partial z}\right|_{z=l}+\alpha_{1}\left(x_{2}(l, t)-x_{1}(l, t)\right)
\end{aligned}
$$

hence, from (14) it follows that the manipulated variable $u_{1}$ appears linearly in the first time derivative of the controlled variable $y(t)$. This suggests requesting a firstorder dynamical behavior between an external variable $y^{d}(t)$ and the controlled output $y(t)$, i.e.

$$
\tau \frac{d y(t)}{d t}+y(t)=y^{d}(t)
$$

where $\tau$ is the desired time constant.

Now, Assumption 1 ensures that

$$
\left.\frac{\partial x_{1}(z, t)}{\partial z}\right|_{z=l} \neq 0
$$

thereafter, the substitution of the first time derivative of the controlled output $y(t)$ by its expression (14) into (15), and by solving the resulting equation with respect to the manipulated variable $u_{1}$, the following control law results

$$
u_{1}=\frac{y(t)-y^{d}(t)+\tau \alpha_{1}\left(x_{2}(l, t)-x_{1}(l, t)\right)}{\left.\tau \frac{\partial x_{1}(z, t)}{\partial z}\right|_{z=l}}
$$

with $y(t)=x_{1}(l, t)$.

Remark 2: The developed control law (17) involves the first spatial derivative of the state $x_{1}$ at $z=l$, which can be approximated by the following finite difference at right

$$
\begin{aligned}
& \left.\frac{\partial x_{1}(z, t)}{\partial z}\right|_{z=l}= \\
& \frac{x_{1}(l, t)-4 x_{1}(l-\Delta z, t)+3 x_{1}(l-2 \Delta z, t)}{2 \Delta z}
\end{aligned}
$$

where $\Delta z$ is the discretization spatial step.

Hence, for practical implementation, one needs the measurements at both positions $z=l-\Delta z$ and $z=$ $l-2 \Delta z$. These measurements can be provided from the measurement of the controlled output $y(t)=x_{1}(l, t)$ using an observer.

\subsection{Closed-loop stability}

The control law (17) yields, in closed-loop, the finite dimensional system (15), which is externally stable. In this subsection, the internal stability of the resulting closed-loop system (15) is analyzed.

The internal representation of the resulting closedloop is obtained by substituting the manipulated variable $u_{1}$ by its expression (17) into the system to be controlled (1)-(6). In this case, the closed-loop can be written under the form operator (8) with

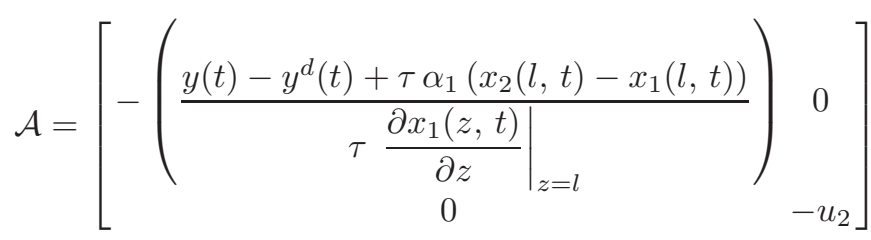

and $\mathcal{B}$ remains unchanged.

Note that, since the obtained control law (17) is of finite dimensional nature, hence the obtained closed-loop can be assumed as a bilinear parameter-varying system (Briat, 2015). Thus, according to the development given in Section 3, if the eigenvalues of the matrix (19) are negative, consequently the closed-loop (15) is internally stable. The condition that ensures the stability of the matrix (19) is provided by Proposition 1 .

Proposition 1: If $\tau \geq 1 / \alpha_{1}$, the eigenvalues of the operator (19) are negative.

Proof. Since $u_{2}>0$, it remains to show that

$$
\frac{y(t)-y^{d}(t)+\tau \alpha_{1}\left(x_{2}(l, t)-x_{1}(l, t)\right)}{\left.\tau \frac{\partial x_{1}(z, t)}{\partial z}\right|_{z=l}}
$$

is positive.

Assumption 1 implies that

$$
\left.\frac{\partial x_{1}(z, t)}{\partial z}\right|_{z=l}>0
$$

and since the time constant $\tau>0$, consequently the denominator of (20) is positive.

To have the condition (20) satisfied, it remains to show that the numerator of (20) is also positive, that is,

$$
\tau \alpha_{1}\left(x_{2}(l, t)-x_{1}(l, t)\right)>y^{d}(t)-y(t)
$$

Now, if $y^{d}(t)-y(t)>0$, according to Remark 1 , it follows that the condition (22) holds since both $\tau$ and $\alpha_{1}$ are positive, consequently the numerator of (20) is positive.

If $y^{d}(t)-y(t)<0$, that is, $y^{d}(t)-x_{1}(l, t)<0$, the numerator of $(20)$ is positive if the following condition holds

$$
\tau \alpha_{1}\left(x_{2}(l, t)-x_{1}(l, t)\right)>\left|y^{d}(t)-y(t)\right|
$$


According to Remark 1, we have

$$
x_{2}(l, t)>x_{1}(l, t)
$$

and since

$$
x_{1}(l, t) \geq y^{d}(t)
$$

therefore

$$
x_{2}(l, t)-x_{1}(l, t)>\left|y^{d}(t)-y(t)\right|
$$

If we take $\tau$ such as $\tau \alpha_{1} \geq 1$, that is, $\tau \geq 1 / \alpha_{1}$, then

$$
\tau \alpha_{1}\left(x_{2}(l, t)-x_{1}(l, t)\right) \geq x_{2}(l, t)-x_{1}(l, t)
$$

and according to (26), one concludes that

$$
\tau \alpha_{1}\left(x_{2}(l, t)-x_{1}(l, t)\right)>\left|y^{d}(t)-y(t)\right|
$$

which implies that the numerator of (20) is positive.

Remark 3: From Proposition 1, it follows that the internal stability condition is related to the choice of the tuning parameter $\tau$ of the control law (17).

\section{Application example}

In this section, the performance of the designed control law is evaluated in the case of the co-current heat exchanger depicted in Figure 1. A cold fluid enters at temperature $T_{c, 0}$ and flows through the internal tube, of length $l$, with a velocity $v_{c}$.

This cold fluid exchanges heat with the hot fluid that flows in the external tube, in the same direction as the cold fluid, with a velocity $v_{h}$. The hot fluid enters at temperature $T_{h, 0}$. The cold and hot fluids leave at temperatures $T_{c, l}$ and $T_{h, l}$, respectively. The dynamic behavior of the co-current heat exchanger is described by the following system of one dimensional linear hyperbolic PDE energy balances (Maidi et al., 2010)

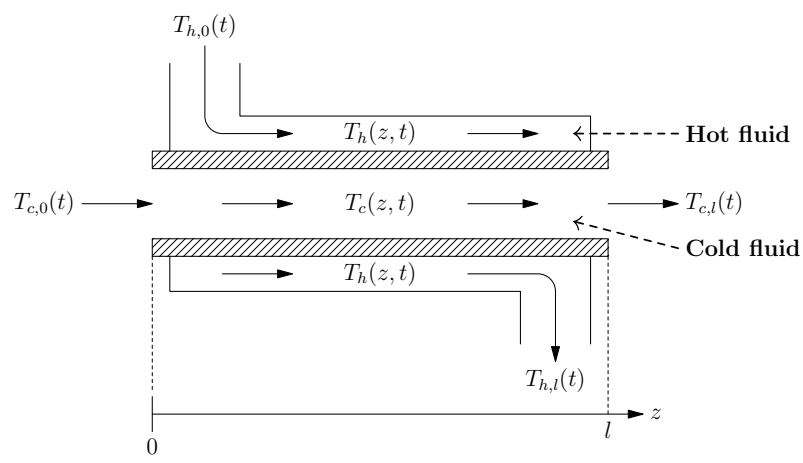

Figure 1: Co-current heat exchanger.

$$
\begin{aligned}
\frac{\partial T_{h}(z, t)}{\partial t} & =-v_{h} \frac{\partial T_{h}(z, t)}{\partial z}+\alpha_{h}\left(T_{c}(z, t)-T_{h}(z, t)\right) \\
\frac{\partial T_{c}(z, t)}{\partial t} & =-v_{c} \frac{\partial T_{c}(z, t)}{\partial z}+\alpha_{c}\left(T_{h}(z, t)-T_{c}(z, t)\right) \\
T_{h}(0, t) & =T_{h, 0}(t) \\
T_{c}(0, t) & =T_{c, 0}(t) \\
T_{h}(z, 0) & =T_{h}^{0}(z) \\
T_{c}(z, 0) & =T_{c}^{0}(z)
\end{aligned}
$$

where $T_{h}(z, t)$ and $T_{c}(z, t)$ are the temperatures of the hot and cold fluids, respectively. $\alpha_{h}$ and $\alpha_{c}$ are the heat transfer coefficients. $T_{h}^{0}$ and $T_{c}^{0}$ are the initial spatial temperature profiles of the hot and cold fluids, respectively.

Let us assume that the objective is to control the outlet cold fluid temperature, that is,

$$
\begin{aligned}
y(t) & =\left.T_{c}(z, t)\right|_{z=l} \\
& =T_{c, l}(t)
\end{aligned}
$$

by manipulating the velocity $v_{c} . T_{h, 0}, T_{c, 0}$ and $v_{h}$ represent external disturbances that affect the heat exchanger.

In this case, both assumptions 1 and 2 hold for the co-current heat exchanger since $T_{c}(z, t)$ is a monotonic increasing function with respect to $z$ and, $\forall t \in[0, \infty), T_{h}(z, t)-T_{c}(z, t)>0$. Consequently, the proposed design methodology can be applied.

According to the development given in the Subsection 4.1, the following state feedback results

$$
v_{c}=\frac{T_{c, l}(t)-T_{c, l}^{d}(t)+\tau \alpha_{c}\left(T_{h}(l, t)-T_{c}(l, t)\right)}{\left.\tau \frac{\partial T_{c}(z, t)}{\partial z}\right|_{z=l}}
$$

The performances are evaluated by simulation and the closed-loop system is simulated using the method of lines (Vande Wouwer et al., 2001) by assuming a number of discretization points equal to 100. The spatial derivatives are approximated using finite differences.

The parameters of the heat exchanger are summarized in Table 1. The initial temperature profiles $T_{h}^{0}(z)$ and $T_{c}^{0}(z)$ are the spatial profiles at steady-state obtained by considering the boundary conditions and the velocities reported in Table 2 . The controller tuning parameter $\tau$ that satisfies the condition of Proposition 1 is taken equal to $6 \mathrm{~s}$.

In the performed simulation runs, to avoid sudden variations of the controlled output $T_{c, l}(t)$, the desired set-point $T_{c, l}^{d}(t)$ is smoothed using a first-order filter that yields the filtered set-point or reference trajectory $T_{c, l}^{f d}(t)$, i.e.

$$
\tau_{f} \frac{d T_{c, l}^{f d}(t)}{d t}+T_{c, l}^{f d}(t)=T_{c, l}^{d}(t)
$$




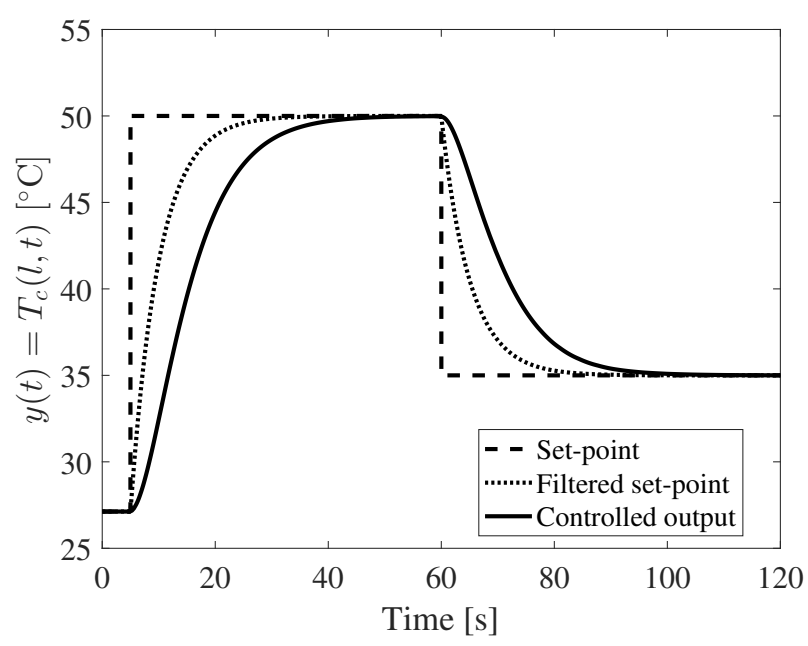

Figure 2: Set point tracking: evolution of the outlet cold fluid temperature $T_{c_{l}}(t)$.

where $\tau_{f}$ is the time constant of the filter taken equal to $5 \mathrm{~s}$. Thus, considering the filtered set point $T_{c, l}^{f d}(t)$ instead of the set point $T_{c, l}^{d}(t)$, the control law (37) takes the following form

$$
v_{c}=\frac{T_{c, l}(t)-T_{c, l}^{f d}(t)+\tau \alpha_{c}\left(T_{h}(l, t)-T_{c}(l, t)\right)}{\left.\tau \frac{\partial T_{c}(z, t)}{\partial z}\right|_{z=l}}
$$

Remark 4: According to proposition 1, the condition of the choice of $\tau$ ensures that both $v_{h}$ and $v_{c}$ have the same sign (both positive). This means physically that both cold and hot fluids flow in the same direction, which is characteristic of a co-current heat exchanger.

\subsection{Set point tracking}

The first simulation run deals with the tracking problem. Thus, in order to evaluate the tracking capability of the control law (39), two step set points $T_{c}^{d}(t)=50^{\circ} \mathrm{C}$ and $T_{c}^{d}(t)=35^{\circ} \mathrm{C}$ have been specified at $t=5 \mathrm{~s}$ and $t=60 \mathrm{~s}$, respectively. Figure 2 shows clearly that the outlet cold fluid temperature $T_{c, l}(t)$ tracks perfectly the imposed set point. The output-tracking is achieved with a smooth evolution of the velocity $v_{c}$ (Figure 3 ). The performance of controller is confirmed by the $3 \mathrm{D}$ temperature profiles given by Figure 4 .

\subsection{Disturbance rejection}

The second performed test deals with disturbance rejection. For this test, a sudden change of $-60 \%$ of the

Table 1 Heat exchanger parameters.

\begin{tabular}{ll}
\hline Parameter & Value \\
\hline \hline$\alpha_{h}$ & $0.3\left[\mathrm{~s}^{-1}\right]$ \\
$\alpha_{c}$ & $0.2\left[\mathrm{~s}^{-1}\right]$ \\
$l$ & $1.0[\mathrm{~m}]$ \\
\hline
\end{tabular}

Table 2 Boundary conditions and steady-state velocities.

\begin{tabular}{ll}
\hline Variable & Value \\
\hline \hline$T_{h, 0}$ & $80\left[{ }^{\circ} \mathrm{C}\right]$ \\
$T_{c, 0}$ & $25\left[{ }^{\circ} \mathrm{C}\right]$ \\
$v_{h}$ & $10\left[\mathrm{~m} \cdot \mathrm{s}^{-1}\right]$ \\
$v_{c}$ & $5\left[\mathrm{~m} \cdot \mathrm{s}^{-1}\right]$ \\
\hline
\end{tabular}

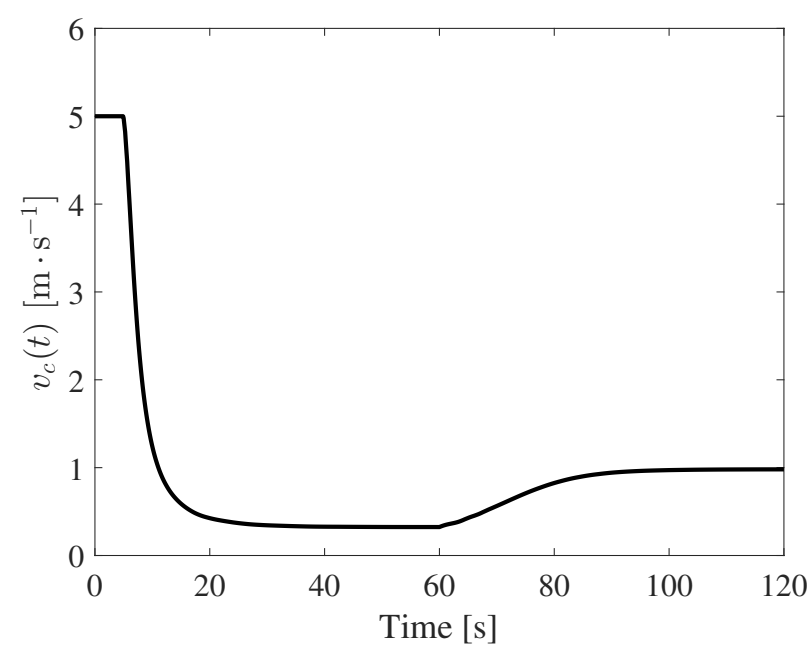

Figure 3: Set point tracking: evolution of the cold fluid velocity $v_{c}(t)$.

hot fluid velocity $v_{h}$ is applied at $t=10 \mathrm{~s}$. Figure 5 shows variations of the cold fluid temperature at some positions along the heat exchanger. From the obtained results, one clearly notices that the disturbance effect observed at $z=0$ is attenuated and becomes invisible at the outlet $z=1$ of the heat exchanger (Figure 5), that is, on the controlled variable. This attenuation is achieved by a slight variation of the cold fluid velocity $v_{c}$ as shown by Figure 6.

Remark 5: From a practical point of view, the velocity or flow rate variation is achieved by a valve that is characterized by a limited range. This means that some desired temperatures cannot be achieved if they need variations that exceed the specified range of the valve or an important inlet hot fluid temperature. Thereby, the analysis of the controllability and reachability properties of the heat exchanger is an important step to specify the set of the reachable set points. These questions, that have been investigated in the literature (Alotaibi et al., 2004; Sano, 2007), are out of the scope of the present work.

\section{Conclusion}

The control of a linear $2 \times 2$ system of hyperbolic PDEs issued from first principles balances, based on the input-output linearization approach, is investigated in this paper. The manipulated variable is taken as a parameter of the system to control a boundary 

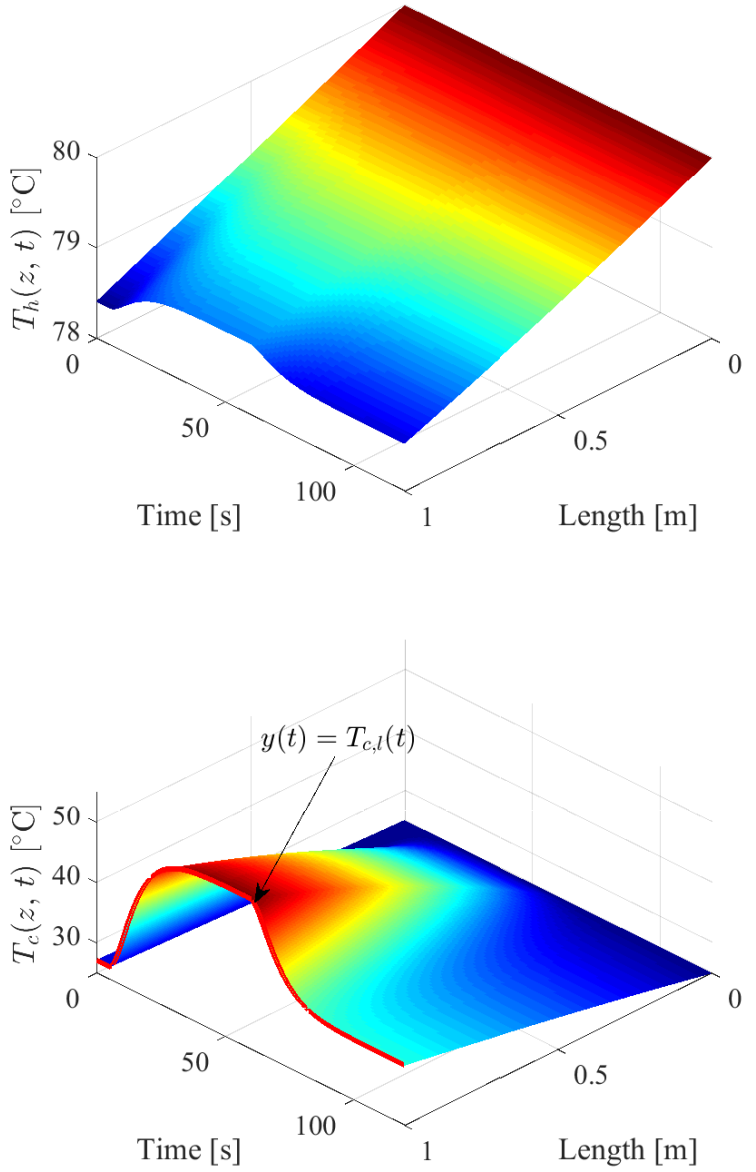

Figure 4: Set point tracking: 3D temperature profiles. Top: hot fluid temperature profile. Bottom: cold fluid temperature profile.

output. This control configuration transforms the system equations as a bilinear DPS. Then, based on the notion of characteristic index that is a generalization to the infinite dimensional systems of the well-known concept of relative degree, a control law, of finite dimensional nature, that ensures both tracking output and disturbance rejection is developed. This control law yields a linear time-varying $2 \times 2$ system of hyperbolic balance laws in closed loop. The stability condition of the closed-loop is derived based on the stability of the eigenvalues of the spatial operator in closed loop.

The tracking and disturbance rejection capabilities of the control law developed are evaluated through numerical simulation runs in the case of a co-current heat exchanger. The obtained results show that the stated feedback achieves good performance in both output tracking and disturbance rejections.

\section{References}

S. Alotaibi, M. Sen, B. Goodwine, and K. T. Yang. Controllability of cross-flow heat exchangers.
International Journal of Heat and Mass Transfer, 47 (5):913-924, 2004.

F. Jr. Ayres. Theory And Problems Of Differential Equations. Schaum's Outline. McGraw-Hill, New York, 1952.

K. Bartecki. Modeling and Analysis of Linear Hyperbolic Systems of Balance Laws. Springer, Switzerland, 2016.

C. Briat. Linear Parameter-Varying and TimeDelay Systems: Analysis, Observation, Filtering and Control. Springer-Verlag, Berlin, 2015.

E. Bühler and D. Franke. Topics in Identification and Distributed Parameter Systems. Springer, Wiesbaden, 1980.

G. Chen, I. Lasiecka, and J. Zhou. Control of Nonlinear Distributed Parameter System. CRC Press, New York, 2001.

P. D. Christofides. Nonlinear and Robust Control of PDE Systems: Methods and Applications to TransportReaction Processes. Birkhäuser, Boston, 2001a.

P. D. Christofides. Control of nonlinear distributed process systems: Recent developments and challenges. AIChE Journal, 47(3):514-518, 2001b.

P. D. Christofides and P. Daoutidis. Feedback control of hyperbolic PDE systems. AIChE Journal, 42(11): 3063-3308, 1996.

R. F. Curtain and H. Zwart. An Introduction to InfiniteDimensional Linear Systems Theory. Springer-Verlag, New York, 1995.

X.-S. Dai, S.-P. Tian, and Y.-J. Guo. Iterative learning control for discrete parabolic distributed parameter systems. International Journal of Automation and Computing, 12(3):316-322, 2015.

A. Diagne, G. Bastin, and J.-M. Coron. Lyapunov exponential stability of 1-D linear hyperbolic systems of balance laws. Automatica, 48(1):109-114, 2012.

D. Ding and X. Gu. Boundary predictive control of second-order linear modulus-vary distributed parameter systems based on wavelets transformation. International Journal of Modelling, Identification and Control, 9(1-2):129-135, 2010.

S. Dubljevic, P. D. Christofides, and I. G. Kevrekidis. Distributed nonlinear control of diffusion-reaction processes. International Journal of Robust and Nonlinear Control, 14(2):133-156, 2004.

K.-J. Engel and R. Nagel. A Short Course on Operator Semigroups. Springer, New York, 2006.

J. P. García-Sandoval, V. González-Álvarez, and C. Pelayo-Ortiz. Robust continuous velocity control of convective spattially distributed systems. Chemical Engineering Science, 63(17):4373-4385, 2008. 

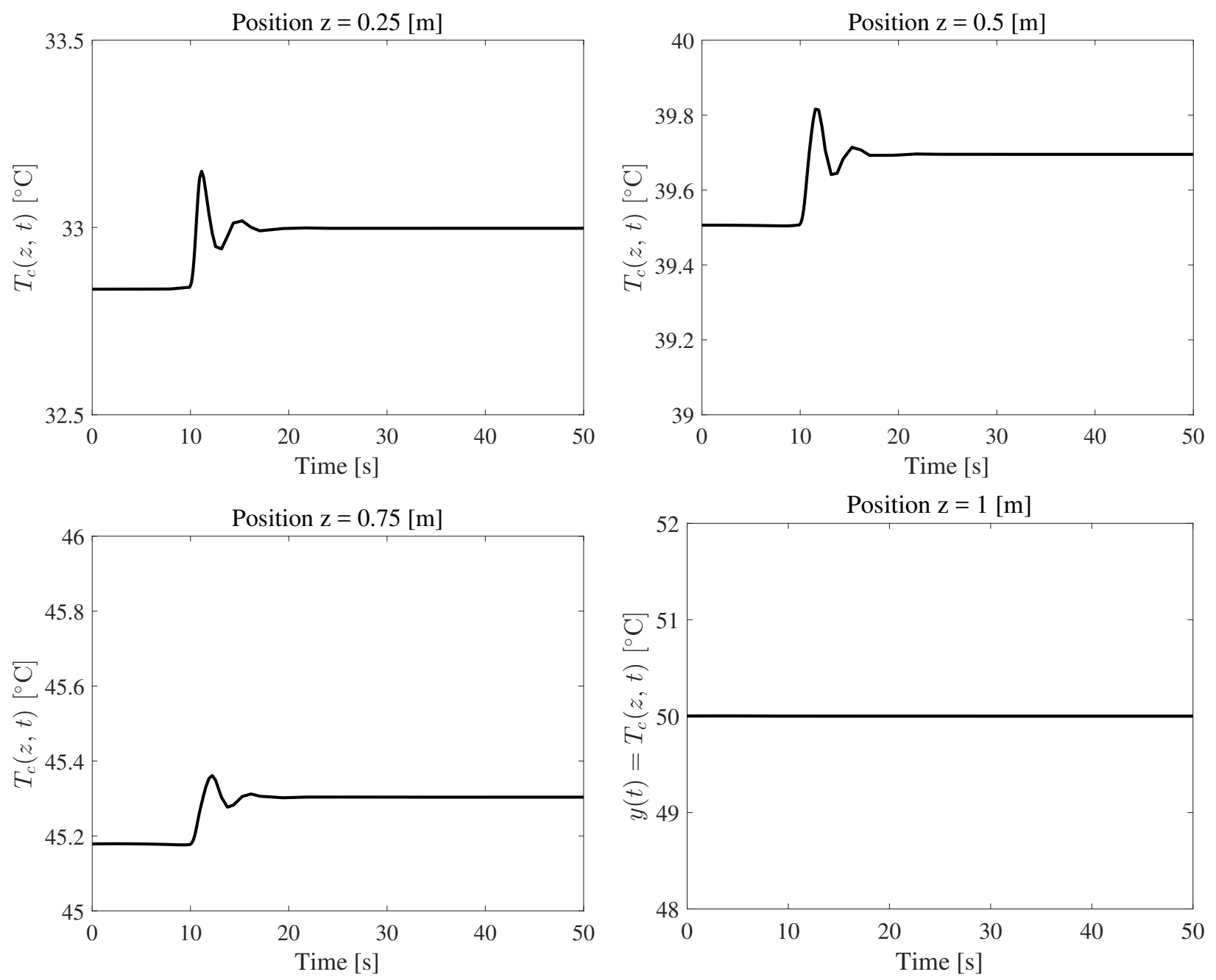

Figure 5: Disturbance rejection: effect of the disturbance $v_{h}(t)$ on the cold temperature $T_{c}(z, t)$ at some positions in the internal tube.

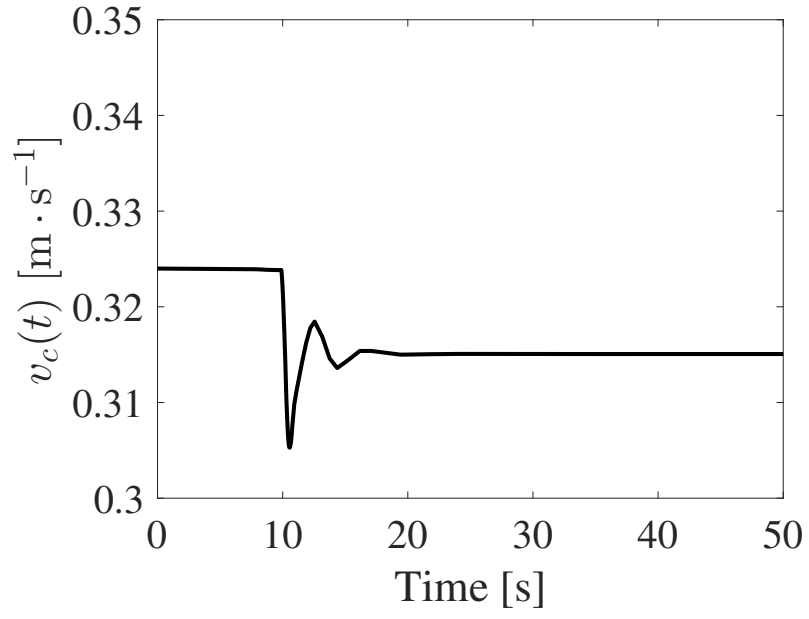

Figure 6: Disturbance rejection: evolution of the cold fluid velocity $v_{c}(t)$.

P. K. Gundepudi and J. C. Friedly. Velocity control of hyperbolic partial differential equation systems with single characterstic variable. Chemical Engineering Science, 53(24):4055-4072, 1998.

E. M. Hanczyc and A. Palazoglu. Sliding mode control of nonlinear distributed parameter chemical processes. Industrial \& Engineering Chemistry Research, 34(2): 557-566, 1995.

A. Isidori. Nonlinear Control Systems. Springer-Verlag, New York, 1995.

H. X. Li and C. Qi. Modeling of distributed parameter systems for applications-A synthesized review from time-space separation. Journal of Process Control, 20 (8):891-901, 2010.

A. Maidi and J. P. Corriou. Boundary control of nonlinear distributed parameter systems by inputoutput linearization. In the Proceedings of the 18th IFAC World Congress, Milan, Italy, pages 1091010915, August 28-September 02, 2011.

A. Maidi and J. P. Corriou. Distributed control of nonlinear diffusion systems by input-output 
linearization. International Journal of Robust and Nonlinear Control, 24(3):386-405, 2014.

A. Maidi, M. Diaf, and J.-P. Corriou. Boundary control of a parallel-flow heat exchanger by input-output linearization. Journal of Process Control, 20(10):11611174,2010 .

M. Ouzahra. Approximate and exact controllability of a reaction-diffusion equation governed by bilinear control. European Journal of Control, 32:32-38, 2016.

R. Padhi and S. Faruque Ali. An account of chronological developments in control of distributed parameter systems. Annual Reviews in Control, 33(1):59-68, 2009

W. H. Ray. Advanced Process Control. Butterworths, Boston, 1989.

D. L. Russell. Controllability and stabilizability theory for linear partial differential equations: Recent progress and open questions. SIAM Review, 20(4): 639-739, 1978.

H. Sano. Observability and reachability for parallelflow heat exchanger equations. IMA Journal of Mathematical Control and Information, 24(1):137147, 2007.

A. Singh and J. Hahn. Effect of finite-dimensional approximation on observability analysis of distributed parameter models. In the Proceedings of the 8th IFAC Symposium on Dynamics and Control of Processes Systems, Cancun, Mexico, pages 199-204, June 6-8, 2007.

A. Vande Wouwer, Ph. Saucez, and W. E. Schiesser Adaptive Method of Lines. Chapman and Hall/CRC, New York, 2001.

M.-L. Wang, N. Li, and S.-Y. Li. Model-based predictive control for spatially-distributed systems using dimensional reduction models. International Journal of Automation and Computing, 8(1):1-7, 2011.

$\mathrm{X} . \mathrm{Xu}$ and S. Dubljevic. The state feedback servoregulator for countercurrent heat exchanger system modelled by sytem of hyperbolic PDEs. European Journal of Control, 29:51-61, 2016. 